\title{
MEDICO - BIOLOGICAL GROUNDS OF THE SOCIAL COHERENCE IN THE SOCIAL WORKER - CLIENT INTERACTION
}

\author{
M. Shoshev, A. Stoykov*, M. Ilieva \\ Department of Social Activities, Faculty of Medicine, Trakia University, Stara Zagora, Bulgaria
}

\begin{abstract}
This article deals with problems related with the role of the social coherence in the Social WorkerClient interaction. Special attention is drawn to the medico-biological principles of the social coherence as a process facilitating the interaction in this system.

Modern concepts for an effective communication include not only the successful verbal transmission and reception of information, but also perception of the emotions by both parties, i.e. the person transmitting the information and the person receiving the information.
\end{abstract}

Key words: empathy, heart rate variability, emotions

\section{INTRODUCTION}

Empathy, defined as the ability to understand the emotions, feelings and thoughts of the other people according to their degree of manifestation, is strictly individual. It lies at the basis of the constructive social interaction. Three types of empathy are known, i.e. cognitive, emotional and intellectual empathy, of which the Social Worker in his/her work should develop better the emotional empathy, without however neglecting the significance of the other two types.

The human ability for a concurrent experience of the emotions and feelings of others is at the basis of the emotional empathy. This ability allows to correctly "interpret" the slightest external manifestation of the emotions and feelings of other people, e.g. voice pitch loudness and intonation, facial expressions, gestures and other non-verbal signs.

This kind of empathy is also known as "emotional contagion". Emotional empathy depends significantly also on the individual's inner "settings", individual's own attitude towards their own thoughts and feelings, expressed by individual's emotions and emotional state, reflected image of other

\footnotetext{
*Correspondence to: Anton Stoykov, Trakia University, Faculty of Medicine, Department of Social Activities, 11 "Armeiska" street, 6000, Stara Zagora, Bulgaria, telephone: 0884737741, e-mail: stoykov70@abv.bg
}

people's emotions, or conveyance of the individual's own emotional state to the others. The emotional empathy plays a very important role in the caring professions, one of which is Social Work.

\section{DISCUSSION}

There comes the question whether conveyance of emotional state from person to person is able to affect also the individual's physical and mental state?

A study carried out in 2015 by DeWayne, P.Williams, ClaudiaCash, Cameron Rankin, Anthony Bernardi, Julian Koenig and Julian F. Thayer in the USA examines the model of neuro-visceral integration and suggests that heart rate variability represents the psychophysiological index of the inhibitory control by the parasympathetic division of the autonomic nervous system and therefore is associated with the emotion regulation capacity.

Emotional regulation is defined as a process in which people change their emotional state and respectively their corresponding physiological body response (1).

Emotional reactions which correspond to the changes in the environment are adaptive responses which "promote" the mental and physical well-being and health. Impulsive emotional reactions which do not correspond to these changes trigger the opposite effectthey do not allow the body to adapt to these changes. 
Another study in this context carried out in 2014 in the USA by Rollin McCraty and Maria Zayas (2), examines the heart-brain communication and also their connection with the cognitive and emotional functions and selfregulation capacity. Examined is the hypothesis that the self-generated positive emotions increase the coherence in body processes, which is reflected in the heartbeat patterns and its coherence. This change in the variability of the heart frequency plays a significant part in the body control; it facilitates the higher cognitive functions and creates a state of relaxation and emotional stability. This results in a state of inner balance, a kind of implicit memory which organizes perception, feelings and behavior.

It has become clear that there are obvious benefits to interacting with individuals who have a high level of coherence between their emotions, emotional state and physiological condition, expressed in an increased variability of the heart rate.

There is a natural tendency towards good communication between people who get along well.

Social coherence is the stable alignment of relationships among individuals, allowing an efficient flow and utilization of energy required for communication, collective cohesion and actions (3).

Social coherence involves the same principles of organization and regulation which are also applicable for the personal coherence, however in the context of establishing relationships among two or more individuals and managing these relations. In a coherent group every member enjoys the freedom to perform their part of the joint process of establishing coherence in order to maintain unity and a positive resonance effect. The impossibility to maintain social coherence affects not only the feelings of the individuals involved in the interaction, but also the psycho-physiological processes in their bodies.

That is why, social coherence reflects the harmonious and stable alignment of relationships, allowing an efficient flow of information and feelings among the people involved in the interaction, as well as the conveyance of an emotional charge needed for the efficient rapprochement and actions.

The constant search and development of new training methods and techniques for further training of higher education specialists in the field of Social Work, is determined mainly by the complexity and multi-aspectness of the object of their profession - the individual who is in a health or social crisis situation.

In this regard, there seems to be some contradiction between the society's need from specialists in the field of Social Work, who have mastered their skills for interpersonal communication and social diagnostics, on one hand, and on the other hand, inadequate development of scientifically grounded systems aiming at the development of these skills.

This fact outlines also the need of increased attention towards development of skills in the individuals working in the Social Work field for interpersonal communication and social coherence, as well as skills for diagnostics of the emotional regulation. Similar skills should be also acquired by the students in Social Work.

Many researchers have found out that the process of interpersonal communication significantly depends on the non-verbal means of communication. Analyzing the phenomenon of "non-verbal communication", particular attention is paid to the term "non-verbal human behavior", seen as socially and biologically justified means for organization of the nonverbal means of communication mastered by the individual, and their transformation into a particular and sensual form of actions and deeds.

In this sense, the effective interaction between the Social Work Specialist and the Client / Patient, is determined not only by how well the words of the interlocutor are understood, but also by the ability to correctly interpret the visual information including interlocutor's look, facial expressions, gestures, body movements, posture, distance, angle, but also speech rhythm and intonation pattern.

Visual information includes also information about the emotional state of the interlocutor as well as the changes in this state, which is an indirect sign for the degree of its regulation. Various emotional manifestations managed by the autonomic nervous system should be well recognized in order to properly interpret them. Such manifestations may include paleness or flushing, sweating, dilated pupils, gooseflesh skin, crying, etc. An important requirement is also the ability to convey one's own positive emotions to the interlocutor, especially in crisis intervention, requiring immediate reaction.

For the successful interpersonal communication in the field of Social Work, 
SHOSHEV M., et al.

students should develop skills for proper interpretation of Kinaesthetics (the study of the body language, including also emotions); Proxemics (the study of distance in the process of communication); and Tacesics (the study of touch in communication) data. It is necessary that the students also learn how to correctly convey their emotions and emotional states and master skills to maintain a positive social coherence.

In the interpersonal communication between the Social Worker specialist and the Client/Patient, communicative tolerance is a requirement for a developing interaction as means of establishing a relationship of trust and as a basis for benevolent attitude towards the Client.

In the opinion of V.V. Boiko, nonestablishment of communicative tolerance and the negative communication attitude, find their expression in behavioral reactions such as the hidden cruelty or outright cruelty towards people, proneness to formulate ungrounded conclusions in the relationships with a partner and upon the observations of the social reality (4).

\section{CONCLUSION}

The authors believe that communicative tolerance appears as a reflection of the positive communication attitude in the speech behavior. This is how he defines the communicative tolerance as a manifestation of social coherence and striving of both parties to contribute to the improvement of the process of interaction.

Communicative attitude is defined as an intellectual predisposition, predisposition to a particular understanding and attitude towards people, objects and events, with whom or which that individual starts communication, and in general, and as an overall predisposition to establish an interaction or showing tendency to avoid verbal contact (5).
This is how social coherence too, in the process of communication facilitates understanding of the position and opinion of the other person and appears as its basis or its foundation. It is displayed at two levels:

- at the level of motivation - value attitude towards the interaction as an equal dialogue, expressed in the degree of emotional regulation by both parties, therefore indirectly affecting the psycho-physiological processes in the body, on the one hand, and

- at the level of its manifestation in the communicative behavior which is a non-verbal manifestation of the cognitive processes.

\section{REFERENCES}

1. DeWayne,Williams, P., Claudia Cash, Cameron Rankin, Anthony Bernardi, Julian Koenig, Julian F.Thayer, Resting heart rate variability predicts self-reported difficulties in emotion regulation: a focus on different facets of emotion regulation, Frontiers in Psychology March 2015 Volume6, Article 261

2. Rollin McCraty, Maria A. Zayas, Cardiac coherence, self-regulation, autonomic stability, and psychosocial well-being, Frontiers in Psychology, Sep 2014 Volume5, Article 1090

3. Bradley, R.T., Charisma and Social Structure: A Study of Love and Power, Wholeness and Transformation. 1987, New York: Paragon House.

4. Boyko, V.V., Energia emocii v obstenii: vzglad na sebya I na drugih., Moskva, 1996, Izd Filin. / Boiko, V.V., The energy of emotions in communication: a look at yourself and others, Moscow, 1996, Filin Publishers

5. Ivanova,L.,A. Skorovodnikova, E. Shiryaeva i dr., 2003 Kultura russkoi rechi: Enciklopedicheskii slovar - spravochnik/ M.: Flinta; Nauka / Ivanova,L.,A. Skorovodnikova, E. Shiryaeva and others, 2003, Culture of Russian language: Encyclopedic dictionary - directory, M.: Flinta; Nauka 